\title{
CD171 multi-epitope peptide design based on immunoinformatics approach as a cancer vaccine candidate for glioblastoma
}

\author{
Seyed Amir Hossein Mohammadzadeh Hosseini Moghri ${ }^{1}$, Arefeh Abbasian ${ }^{2}$ \\ ${ }^{1}$ Department of Microbial Biotechnology, Faculty of Biotechnology, Amol University of Special \\ Modern Technologies, Amol, Iran \\ ${ }^{2}$ Department of Biology, Faculty of Basic Sciences, Semnan University, Semnan, Iran
}

Corresponding author: Seyed Amir Hossein Mohammadzadeh Hosseini Moghri

\begin{abstract}
Glioblastoma (GB) is a common primary malignancy of the central nervous system, and one of the highly lethal brain tumors. GB cells can promote therapeutic resistance and tumor angiogenesis. The CD171 is an adhesion molecule in neuronal cells that is expressed in glioma cells; it is a regulator of the brain development. CD171 is one of the immunoglobulin-like CAMs (cell adhesion molecules) families that can be associated with prognosis in a variety of human tumors. The multi-epitope peptide vaccines are based on synthetic peptides with a combination of both B-cell epitopes and T-cell epitopes, which can induce specific humoral or cellular immune responses. In the present study, several immune-informatics tools were used for analyzing the CD171 sequence and studying the important characteristics of a designed vaccine. The results included the prediction and validation of the secondary and tertiary structure, physicochemical properties, solubility, conservancy, toxicity as well as antigenicity and allergenicity of the promising candidate for a vaccine against CD171. The immunoinformatic analysis suggested 12 predicted multi-epitope peptides, whose construction consists of 582 residues long. Therewith, cloning adaptation of designed vaccine was performed and eventually sequence was inserted into pET30a (+) vector for the application of the anti-glioblastoma vaccine development.
\end{abstract}

Keywords: immuno-bioinformatics, CD171, vaccine, epitope predictions, glioblastoma. 


\section{Introduction:}

Glioblastoma (GB) is the most aggressive type of glioma and corresponding to the majority of primary central nervous system (CNS) malignancy form in adults. GB supposed to respond for more than $50 \%$ of all intracranial malignancies (1). CD171 plays a regulating role in neural cell development, tumor cell survival and migration (2). Researchers have proven the overexpression of CD17 in solid tumors, such as gliomas and colorectal cancer, as a prognostic factor (3). CD171 is a 200 to $220 \mathrm{kDa}$ multidomain type 1 membrane glycoprotein, containing a cytoplasmic intracellular domain, a transmembrane domain, and six immunoglobulin-like and five fibronectin-repeat in the extracellular domain. This glycoprotein has a regulatory function in cell adhesion, development, survival, and metastasis of tumor cells (4, 5). CD171 ectodomain is abnormal in tumor cells, due to cleavage by the ADAM10 protease and consequent auto stimulation, resulting in cellular motility and proliferation $(6,7,8)$. Currently, considering the various advantages of multi-epitope peptide-based vaccine, which consists of high specificity, good safety, stability, ease of production and storage, it has become an area of increasing interest in the field of vaccine research; this is even more promising in light of advances in immunoinformatics and vaccinology (9). Multi-epitope peptide vaccines are based on synthetic peptides with a combination of many B-cell and T-cell epitopes that can induce specific humoral and/or cellular immune responses. Prediction of B- and T-cell epitopes has been the focus of computational vaccinology and, given the potential translational implications, several bioinformatics tools have been developed $(10,11)$. The aim of the present study is to analyze, using computational methods, the sequence and structure of CD171 and to predict potential linear epitopes of CD171 that may be targets of B and T-cells. This multi-epitope design will provide information for a promising peptide vaccine based on the epitope for cancer therapy. 


\section{Materials and Methods:}

\subsection{CD171 sequence retrieval and structural prediction}

The amino acid sequences of CD171 with accession number: NP_001265045.1 were retrieved from the NCBI database in FASTA format (12). TMHMM tool was used to demonstrate if the peptides are in transmembrane regions or not. TMHMM supported the hidden Markov model (HMM) method, which specializes in the modeling of globular domains, helix caps and other various regions of cell membrane proteins ( http://www.cbs.dtu.dk/services/TMHMM/)(13).

\subsection{B-cell epitope prediction}

The objective is the prediction of the B cell epitope to find a potential antigen that would interact with B lymphocytes and initiate an immune response (14). The linear B cell epitopes have variable peptide lengths, from 2 to 85 . The BepiPred-2.0 webserver was used to the prediction of linear B cell epitopes (http://www.cbs.dtu.dk/services/BepiPred/). This method is based on a random forest algorithm trained on epitopes annotated from antibody-antigen protein structures (15).

\subsection{T-cell epitope prediction}

The Immune Epitope Database (IEDB), HLA allele frequencies and reference sets with maximum population coverage for the selected epitopes were used. The prediction of the most probable epitopes interacting with different MHC class I, II alleles chosen based on the percentile cut-off was set at 0.5 and 1 for MHC class I and II, respectively. In both cases, to find a good binding affinity, the cut-off value IC50 was set at lower $50 \mathrm{~nm}$ and $150 \mathrm{~nm}$ to obtain a 
better level of confidence in the prediction of epitopes for MHC class I and II, respectively, and the antigenicity score. The candidate epitopes for MHC class I were determined by both IEDB and NetMHCpan EL 4.0 methods, and for MHC class II by IEDB 2.22 recommended method binding prediction tool (http://tools.iedb.org/mhci/), (http://tools.iedb.org/mhcii/)(16).

\subsection{Antigenicity, conservancy, allergenicity and toxicity extrapolation}

The antigenicity characteristics of the peptide were screened using an online antigen prediction server, VaxiJen v2.0 (http://www.ddgpharmfac.net/vaxijen/). The Threshold for tumor models was set at $\geq 0.4$ (17) and the conservancy of the selected epitopes was examined using the epitope conservancy tool (http://tools.iedb.org/conservancy/) (18). The web-based servers AllerTOP v.2.0 (http://www.ddgpharmfac.net/AllerTOP/) (19) and AllergenFP v.1.0 (http://www.ddg-pharmfac.net/AllergenFP/) (20) were used to prediction of the epitopes allergenicity. The ToxinPred web server was applied for prediction of toxic peptides (https://webs.iiitd.edu.in/raghava/toxinpred). This method was developed based on the machine learning technique and quantitative matrix using different properties of peptides (21).

\subsection{Construction of multi-epitope vaccine candidate sequence}

The candidate vaccine sequence was generated based on the overlapping of the predicted B-cell and T-cell epitopes of the predicted peptide containing linear B- and T-cell epitopes was fused using AAY linkers (22). Using a DPRVPSS linker, the cholera toxin subunit B (CTB) with accession no. CAA53976.1 was chosen as an adjuvant, which was constructed within the final vaccine model at the $\mathrm{N}$-terminal in order to potentiate the immunogenic capacity of our peptide by stimulating the innate immunity. The adjuvant potential of CTB has been reported in several 
animal models, indicating that the adjuvant potential would be scalable to complex species (23). The CTB sequence was retrieved from the UniProt server (http://www.uniprot.org/).

\subsection{P Physicochemical properties and solubility prediction}

Various physicochemical features of candidate peptides which included theoretical pI, qliphatic index, instability index, stimated half-life in the mammalian reticulocytes in vitro, extinction coefficient, molecular weight, and grand average of hydropathicity (GRAVY) were determined using the online web server ProtParam (http://web.expasy.org/protparam/)(24). Estimated solubility in water of the multi-epitope vaccine peptide was evaluated using the Pepcalc (http://pepcalc.com/) (25).

\subsection{Secondary structure prediction}

The secondary structure of final peptide was predicted with Position-specific iterated BLAST (PSI-blast) based on secondary structure PREDiction (PSIPRED), (http://bioinf.cs.ucl.ac.uk/psipred/) (26). Also, the RaptorX Property web server (http://raptorx.uchicago.edu/StructurePropertyPred/predict/) was employed to predict the secondary structure properties of the chimeric protein (27).

\subsection{Tertiary structure prediction and validation}

The homology modeling tool, I-TASSER (Iterative Threading ASSEmbly Refinement) server (https://zhanglab.ccmb.med.umich.edu/I-TASSER/), was applied for three-dimensional (3D) structure prediction of the final multi-epitope vaccine peptide. Through multiple threading alignments and iterative structural assembly simulations, the I-TASSER first generates threedimensional (3D) atomic models from an amino acid sequence (28). Furthermore, we perform 
analysis and visualization by generating a 3D model in PDB format using PyMOL (https://pymol.org/2/) (29).

In addition, the validation of the built model was performed as a vital step to the detection of potential errors in predicted 3D models (30). Subsequently, a Ramachandran plot was generated using the RAMPAGE server (http://mordred.bioc.cam.ac.uk/ rapper/rampage.php). The Ramachandran plot energetically displays visualization of allowed and disallowed dihedral angles psi $(\psi)$ and phi $(\phi)$ of the amino acid and is calculated based on the van der Waal radius of the side chain. The RAMPAGE results demonstrate the percentage of residues in allowed and disallowed regions that define the quality of the modeled structure (31). The entire quality of the final vaccine model was defined by ProSA-web (https://prosa.services.came.sbg.ac.at/prosa.php). ProSA-web provides a protein tertiary structure validation and calculates an overall 3D-structure quality score; if the calculated score is outside the characteristic range of native proteins, the structure is likely to have errors (32).

\subsection{In silico cloning adaptation of designed vaccine}

The Java Codon (JCat) adaptation tool server (http://www.prodoric.de/JCat/) was performed for reverse translation and codon optimization, in order to construct the multi-epitope vaccine in a selected expression vector (33). Codon optimization leads to a higher expression rate of the final vaccine in E. coli K12 as an expression host because the use of the condon of the human and the selected host differs from each other. Three additional options were applied to avoid the transcription of rho-independent termination, prokaryote ribosome binding site and cleavage site of restriction enzymes to increase the efficiency of a translation process. The JCat result includes the codon adaptation index (CAI) and the of percentage GC content, which can be used to 
evaluate protein expression levels. CAI provides information on codon usage biases; the ideal CAI score is 1.0 , however, greater than 0.8 is considered a good score (34). The GC content of a sequence should range between $30-70 \%$ and outside this range is considered unfavorable translational and transcriptional efficiencies (35). To clone the optimized, the final vaccine sequence was reversed and Nde I and Xho I restriction sites were added at the N-and C-terminal sites of the final construct, respectively. Finally, the optimized sequence (with restriction sites) was inserted into the pET-30a (+) vector using SnapGene restriction cloning module to ensure vaccine expression.

\section{Results:}

\subsection{CD171 sequence analysis and structural prediction}

The amino acid sequence of CD171 contains 1257 amino acids, which ectodomain residues ranging from 19 to1120 (the signal peptide was removed), selected using TMHMM (Figure 1).

\subsection{Prediction of B-cell epitopes}

Results using ABCpred server and on the basis of VaxiJen scores showed 29 linear B cell epitopes, varying in peptide lengths from 6 to 37. However, among the 29 predicted linear B cell epitopes, 4 epitopes, including "EASGKPEV”, "WREGSQRKH”, “ PLDEGGKGQ” and "VPKEGQ", had the VaxiJen score of more than one, which indicates the high antigenicity nature of these epitopes and that they can be considered the most potential antigenic B cell epitopes, as shown in supplementary table 1.

\subsection{Prediction of T-cell epitopes}


Among the 95 predicted MHC Class I epitope, 18 epitopes, including "LQANDTGRY", "RGYNVTYWR", "LTDLSPHLRY", "LQANDTGRYF", "RLMAEGAPK, "VTMGQNGNLY", "ETARLDCQV", "FTFSTPEGV", "QVKGHLRGY", "RFQGIYRCF", "SLGSARHAY”, “TFRVTAINK”, "TYWREGSQR", "KTNGTGRVR”, "MAVKTNGTGR”, "GTAMSHEIR", "GSQRKHSKR" and "EVTWRINGI"; and among the 81 predicted MHC

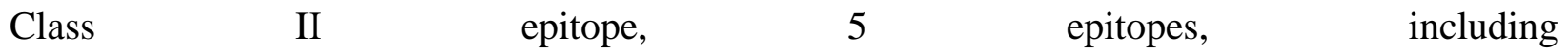
“SFTITGNNSNFAQRF”,“KILHIKQDERVTMGQ”,“ILHIKQDERVTMGQN”,“NSKILHIKQ DERVTM" and, "LHIKQDERVTMGQNG" had the VaxiJen score of more than one, which demonstrates the high antigenicity nature of these epitopes, as shown in supplementary table 2 and 3 respectively.

\subsection{Multi-epitope vaccine}

Taken together, based on the 29 B-cell epitopes and the 176 adjacent T-cell epitopes (95 of Cytotoxic T Lymphocytes (CTL) and 81 of Helper T Lymphocytes (HTL)), a total of 12 candidates for multi-epitope vaccine overlapping peptides were selected, containing both B- and T-cell epitopes. By comparison, the multi-epitope vaccine "QTYMAVQGSTAYLLCKAFGAPVPSVQWLDEDGTTVLQDER" contained eight (highest count) T-cell epitopes. These data and the antigenicity and allergenicity of the vaccine candidates were shown in table 4.

\subsection{Prediction of the physicochemical properties and solubility of the vaccine candidate}

The multiepitope vaccine had an estimated molecular weight of $50 \mathrm{kDa}$, a theoretical isoelectric point (pI) of 5.79, which is below seven, demonstrating a high proportion of negative charge against positively charged residues in the protein. The instability index was determined at 44.75 , 
which indicates instability of solutions. The large average of the hydropathicity index (GRAVY) was -0.429 , indicating that it was a hydrophilic protein; therefore, it can interact in aqueous solutions (35). Aliphatic index was 71.42, indicating that the vaccine can be stable over a wide temperature range. The estimated half-life in mammalian reticulocytes in vitro was 2.8 hours, and $10 \mathrm{~min}$ in yeast and $2 \mathrm{~min}$ in E. coli. The extinction coefficient has been calculated from 81710 to $81960 \mathrm{M}-1 \mathrm{~cm}-1$, which provide support for a quantitative study of protein-ligands and protein-protein interaction in solution, and indicates poor water solubility. The results of the physicochemical properties and also the allergenicity of the candidate peptide are shown in table 5.

\subsection{Multi-epitope vaccine design}

After the prediction of B- and T-cell epitopes, we fused them in order to generate a multi-epitope peptide by using suitable linkers. In order to produce sequences with minimized junctional immunogenicity, AAY linkers were combined between the predicted epitopes. Cholera toxin subunit B (CTB) sequence as an adjuvant was constructed within the final vaccine model at the

N-terminal, using a DPRVPSS linker to improve the immunogenic capacity of the peptides by stimulating the innate immune response. Moreover, to aid in protein purification and identification, a $6 \mathrm{xHis}$ tag was added at the C-terminal. The final vaccine peptide was constructed with 582 residues derived from 12 merged peptide sequences. A schematic diagram of the vaccine is displayed in figure 2 .

\subsection{Secondary structure prediction}

The PSIPRED prediction method was used to predict the secondary structure of the final chimeric peptide, which accomplished output analysis obtained from the PSI-BLAST and was 
submitted in FASTA format. The obtained secondary structure prediction revealed that the protein had to contain $2 \%$ alpha helix, $47 \%$ beta strand, and $49 \%$ coil (Figure 3A). As well, considering the accessibility of the amino acids to solvents, it was predicted that $50 \%$ would be exposed, $32 \%$ exposed to the medium exposed, and 17\% would be buried. The RaptorX Property server predicted a total of 39 residues $(6 \%)$ to be located in disordered domains.

\subsection{Tertiary structure modelling and validation}

In total, five models of tertiary structure of the designed chimeric protein were predicted based on 10 threading templates by the I-TASSER server. The Z-score values of the 10 chosen templates ranged from 0.72 to 12.98 and showed good alignment. The $\mathrm{C}$-score values of five predicted models ranged from -3.11 to -1.16 . The range of $\mathrm{C}$-score value is typically between -5 and 2, with higher values showing higher confidence. The model with the highest C-score was selected from the homology modeling (Figure 3B). This model had an estimated TM-score of $0.53 \pm 0.15$ with an estimated RMSD of 11.2 $\pm 4.6 \AA$. The TM-score has been suggested as a scale for measuring the structural similarity between two structures (35) and to overcome the problem of RMSD, which is sensitive to local error. A TM-score of more than 0.5 indicates a correct topology model. These cut-off values are independent of protein length.

RAMPAGE, a determinative tool, was assigned to evaluate the reliability model, generate Ramachandran plot and determine the energy of the stable conformation of the psi $(\psi)$ and phi (Ф) twisting or dihedral angles for each amino acid. The results of the tertiary structure validation of the Ramachandran plot analysis shows that the number of residues from favorable regions was $69.5 \%$ and, additionally, the allowed region residues were $20.2 \%$, and only $10.3 \%$ of the residues were found in the outlier region. The total percentage of favoured and allowed 
region residues was $89.7 \%$, while more than $90 \%$ is an ideal result to make the mode believable and convincing (Figure 4A). The quality and potential errors in the crude 3D model were verified by ProSA-web, which gave a Z-score of -2.25 for the chosen model of the input vaccine protein (Figure 4B). Both the Ramachandran plot and the ProSA-web score authenticated the quality of the CD171 3D model.

\subsection{In silico cloning adaptation of designed vaccine}

The Java Codon adaptation tool (JCat) was utilized to optimize the use of codons in the vaccine constructed on strains of $\mathrm{E}$. coli $\mathrm{K} 12$, for maximum protein expression and differentiate the human and E. coli expression system. The optimized codon sequence has 1746 nucleotides in length. The Codon Adaptation Index (CAI) of the optimized codon sequence was found to be 0.96. The optimal range of CAI index was between zero to one, showing the probable success of the target gene expression. The GC sequence content was $53.3 \%$, which is also satisfactory because it shows the possibility of good expression of the vaccine candidate in the host E. coli. The ideal percentage range of GC content is between $30 \%$ and $70 \%$. Eventually, using SnapGene software for restriction cloning, the recombinant plasmid sequence was constructed by adding the adapted codon sequences into the pET30a (+) vector between Nde I and XhoI restriction sites (Figure 5).

\section{Discussion}

Malignant gliomas are rare and indicate an incidence of $2.5 \%$ of the leading cause of cancer death (36). Many vaccines against glioblastoma have been examined in cell cultures and animal models, but none have been used for therapeutic application in humans so far $(37,38)$. Epitopebased vaccines as a promising approach have been considered to generate a specific immune 
response and avoid responses against other unfavorable epitopes on the complete antigen (39). Various advantages of this approach include increased safety, the opportunity to rationally engineer the epitopes for increased potency and breadth, and the ability to focus immune responses on conserved epitopes (40). In this research, several precise bioinformatics tools were applied to gather information about the candidate vaccine; the first step was the prediction of Band T-cell epitopes in the protein sequence and, in order to design a multi-epitope peptide vaccine, the selected epitopes were linked using suitable linker sequences (41). To the production of sequences with minimized junctional immunogenicity, AAY linkers (30) were inserted between the predicted epitopes, thus lead to the rational multi-epitope vaccine design construction (41). Also, in order to attain a high level of expression and improved bioactivity of the fusion peptide the DPRVPSS linker was inserted between the adjuvant protein sequence and the designed epitopes. The constructed vaccine candidate indicated that it contains 28 and 25 numbers of high-affinity MHC class I, MHC class II respectively, and 12 number of linear B-cell epitopes by the analysis of immuno-informatics results. The absence of allergenic properties of the designed peptide chimera indicates could be promising potential as a vaccine candidate. The designed multi-epitope vaccine has been shown Vaxijen scores 0.49 and 0.50 , with and without the addition of an adjuvant sequence respectively. Similar antigenicity scores with and without an adjuvant sequence can suggest that it may be valuable to express the chimeric peptide without the adjuvant. As a result, the vaccine candidate molecular weight is $50 \mathrm{kDa}$ and it water solubility was predicted to be poor. In order to many biochemical and functional research, the solubility of the overexpressed recombinant protein in the E. coli host is one of the needed agents (30). The candidate vaccine theoretical pI is predicted to be 5.79 showing that the vaccine is acidic in nature. As well as, the predicted instability index (44.75) which show the stability upon 
expression of the candidate vaccine. The aliphatic index (71.42) indicated that the vaccine has aliphatic side chains, showing potential hydrophobicity. All these above parameters demonstrate the vaccine is thermally stable. Considering the importance of secondary and tertiary structures knowledge in target protein as an essential factor in vaccine design (41) the secondary structure results demonstrated that the protein contained mainly of coils (49\%), with only $6 \%$ of residues disordered. The 3D structure of the vaccine candidate demonstrated desirable properties based on Ramachandran plot predictions. The Ramachandran plot indicates that most of the residues are found in the favoured and allowed regions (89.7\%) with few residues in the outlier region which shows satisfaction about the quality of the overall model. The codon optimization was performed to attain the high-level expression of our recombinant vaccine in E. coli (strain K12). Both the codon adaptability index (0.96) and the GC content (53.3\%) were desirable for high-level expression of the vaccine in bacteria. Eventually to the validation of our immuno-informatics results, the peptide expression in a bacterial system and fulfill the various immunological assays is essential.

\section{Conclusions}

In the formulation of novel drugs or vaccines, immunoinformatics approaches provide new insights and appear as interdisciplinary strings that take different materials to overcome the difficulties related to the long time and high expense on a new therapy development. Herein, several immuno-informatics tools were applied to design a promising vaccine peptide; the suggested vaccine candidate could potentially be used to glioblastoma neoplasm cell elimination.

\section{Conflict of Interest Statement:}

The authors declare a lack of conflict of interest in this research. 


\section{References}

1. Davis FG, Kupelian V, Freels S, et al. Prevalence estimates for primary brain tumors in the United States by behavior and major histology groups. J Neurooncol. 2001;3(3):152-8.

2. Maness PF, Schachner M. Neural recognition molecules of the immunoglobulin superfamily: signaling transducers of axon guidance and neuronal migration. Nat. Neurosci. 2007;10(1):19-26.

3. Boo YJ, Park JM, Kim J, et al. L1 expression as a marker for poor prognosis, tumor progression, and short survival in patients with colorectal cancer. Ann. Surg. Oncol . 2007;14(5):1703-11.

4. Schäfer MK, Altevogt P. L1CAM malfunction in the nervous system and human carcinomas. Cell. Mol. Life Sci. 2010;67(14):2425-37.

5. Siesser PF, Maness PF. L1 cell adhesion molecules as regulators of tumor cell invasiveness. Cell Adh Migr. 2009;3(3):275-7.

6. Riedle S, Kiefel H, Gast D, et al. Nuclear translocation and signalling of L1-CAM in human carcinoma cells requires ADAM10 and presenilin/ $\gamma$-secretase activity. Biochem. J. 2009;420(3):391-402.

7. Gavert N, Ben-Shmuel A, Raveh S, Ben-Ze'ev A. L1-CAM in cancerous tissues. Expert Opin Biol Ther. 2008;8(11):1749-57.

8. Yang M, Li Y, Chilukuri K, Brady OA, Boulos MI, Kappes JC, Galileo DS. L1 stimulation of human glioma cell motility correlates with FAK activation. J Neurooncol. 2011;105(1):27-44.

9. Skwarczynski M, Toth I. Recent advances in peptide-based subunit nanovaccines. Nanomed. 2014;9(17):2657-69.

10. Doytchinova IA, Flower DR. Quantitative approaches to computational vaccinology. Immunol. Cell Biol. 2002;80(3):270-9.

11. Flower DR, McSparron H, Blythe MJ, et al. Computational vaccinology: quantitative approaches. Novartis Found.Symp. 2003: 102-125.

12. Geer LY, Marchler-Bauer A, Geer RC, et al. The NCBI biosystems database. Nucleic Acids Res.2010:1;38: 492-6.

13. Krogh A, Larsson B, Von Heijne G, et al. Predicting transmembrane protein topology with a hidden Markov model: application to complete genomes. J. Mol. Biol. 2001;305(3):567-80.

14. Nair DT, Singh K, Siddiqui Z et al. Epitope recognition by diverse antibodies suggests conformational convergence in an antibody response. J. Immunol. 2002;168(5):2371-82.

15. Jespersen MC, Peters B, Nielsen M, et al. BepiPred-2.0: improving sequence-based B-cell epitope prediction using conformational epitopes. Nucleic Acids Res. 2017;45(W1):W24-9.

16. Zhang Q, Wang $\mathrm{P}$, Kim Y, et al. Immune epitope database analysis resource (IEDB-AR). Nucleic Acids Res. 2008;36(suppl_2):W513-8.

17. Doytchinova IA, Flower DR. VaxiJen: a server for prediction of protective antigens, tumour antigens and subunit vaccines. BMC Bioinform. 2007;8(1):4. 
18. Bui HH, Sidney J, Li W, et al. Development of an epitope conservancy analysis tool to facilitate the design of epitope-based diagnostics and vaccines. BMC Bioinform. 2007;8(1):361.

19. Dimitrov I, Bangov I, Flower DR, et al. AllerTOP v. 2-a server for in silico prediction of allergens. J. Mol. Model. 2014;20(6):2278.

20. Dimitrov I, Naneva L, Doytchinova I, et al. AllergenFP: allergenicity prediction by descriptor fingerprints. Bioinform. 2014;30(6):846-51.

21. Gupta S, Kapoor P, Chaudhary K, et al. In silico approach for predicting toxicity of peptides and proteins. PLoS One. 2013;8(9).

22. Khatoon N, Pandey RK, Prajapati VK. Exploring Leishmania secretory proteins to design B and T cell multi-epitope subunit vaccine using immunoinformatics approach. Sci. Rep. 2017;7(1):1-2.

23. Baldauf KJ, Royal JM, Hamorsky KT, et al. Cholera toxin B: one subunit with many pharmaceutical applications. Toxins. 2015 (3):974-96.

24. Gasteiger E, Hoogland C, Gattiker A, et al. Protein identification and analysis tools on the ExPASy server. InThe proteomics protocols handbook 2005 (pp. 571-607). Humana press.

25. Lear S, Cobb SL. Pep-Calc. com: a set of web utilities for the calculation of peptide and peptoid properties and automatic mass spectral peak assignment. J. Comput. Aided Mol. Des. 2016;30(3):271-7.

26. Buchan DW, Minneci F, Nugent TC, et al. Scalable web services for the PSIPRED Protein Analysis Workbench. Nucleic Acids Res. 2013 Jul 1;41(W1):W349-57.

27. Wang S, Peng J, Ma J, et al. Protein secondary structure prediction using deep convolutional neural fields. Sci. Rep. 2016;6(1):1-1.

28. Roy A, Kucukural A, Zhang Y. I-TASSER: a unified platform for automated protein structure and function prediction. Nat. Protoc. 2010 (4):725.

29. DeLano WL. The PyMOL molecular graphics system. http://www. pymol. org. 2002.

30. Khatoon N, Pandey RK, Prajapati VK. Exploring Leishmania secretory proteins to design B and T cell multi-epitope subunit vaccine using immunoinformatics approach. Sci. Rep. 2017;7(1):1-2.

31. Lovell SC, Davis IW, Arendall III WB, et al. Structure validation by $\mathrm{C} \alpha$ geometry: $\phi, \psi$ and C $\beta$ deviation. Proteins. 2003;50(3):437-50.

32. Wiederstein M, Sippl MJ. ProSA-web: interactive web service for the recognition of errors in threedimensional structures of proteins. Nucleic Acids Res. 2007;35(suppl_2):W407-10.

33. Grote A, Hiller K, Scheer M, et al. JCat: a novel tool to adapt codon usage of a target gene to its potential expression host. Nucleic Acids Res. 2005;33(suppl_2):W526-31.

34. Morla S, Makhija A, Kumar S. Synonymous codon usage pattern in glycoprotein gene of rabies virus. Gene. 2016;584(1):1-6.

35. Ali M, Pandey RK, Khatoon N, et al. Exploring dengue genome to construct a multi-epitope based subunit vaccine by utilizing immunoinformatics approach to battle against dengue infection. Sci. Rep. 2017;7(1):1-3. 
36. Hanif F, Muzaffar K, Perveen K, et al. Glioblastoma multiforme: a review of its epidemiology and pathogenesis through clinical presentation and treatment. Asian Pacific journal of cancer prevention: APJCP. 2017;18(1):3.

37. Oh T, Fakurnejad S, Sayegh ET, et al. Immunocompetent murine models for the study of glioblastoma immunotherapy. J. Transl. Med. 2014;12(1):107.

38. Kindy MS, Yu J, Zhu H, et al. A therapeutic cancer vaccine against GL261 murine glioma. J. Transl. Med. 2016;14(1):1.

39. Moise L, Gutierrez A, Kibria F, et al. iVAX: An integrated toolkit for the selection and optimization of antigens and the design of epitope-driven vaccines. HUM VACC IMMUNOTHER. 2015;11(9):231221.

40. Zhou WY, Shi Y, Wu C, et al. Therapeutic efficacy of a multi-epitope vaccine against Helicobacter pylori infection in BALB/c mice model. Vaccine. 2009;27(36):5013-9.

41. Meza B, Ascencio F, Sierra-Beltrán AP, et al. A novel design of a multi-antigenic, multistage and multi-epitope vaccine against Helicobacter pylori: an in silico approach. Infect. Genet. 2017;49:309-17.

\section{Results (Figures and Tables)}

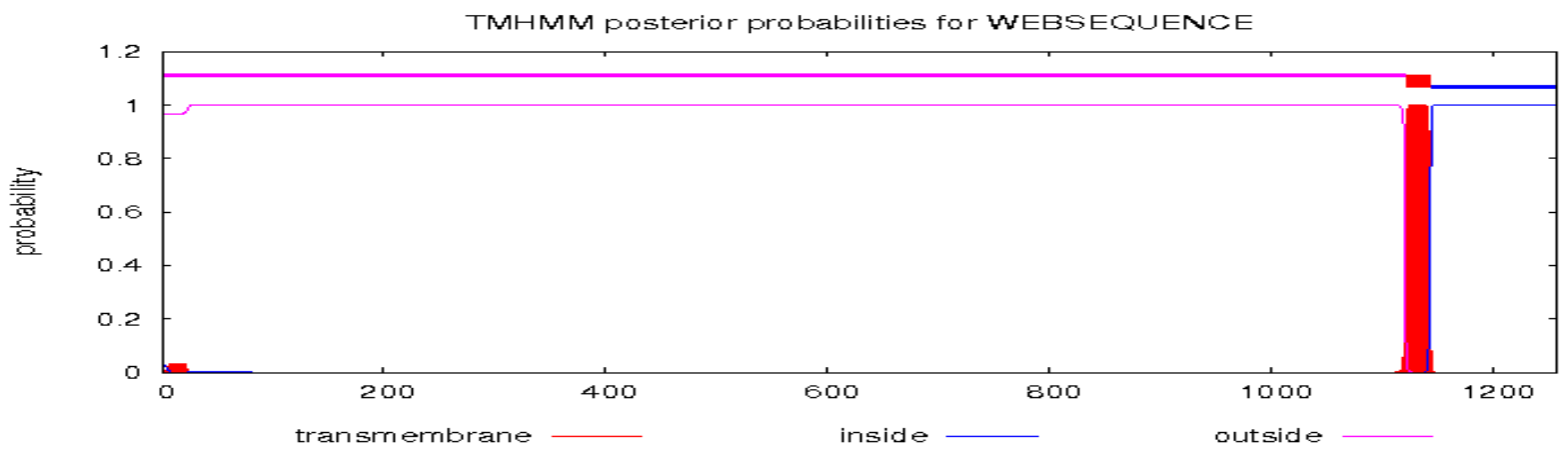

Figure 1. TMHMM was predicted the location of intervened loop regions and the transmembrane helices in the protein topology, from 1to 1120 residue (outside), from 1121to 1143 residue (TMhelix), from 1144to 1257 residue (inside) (Figure 7). 


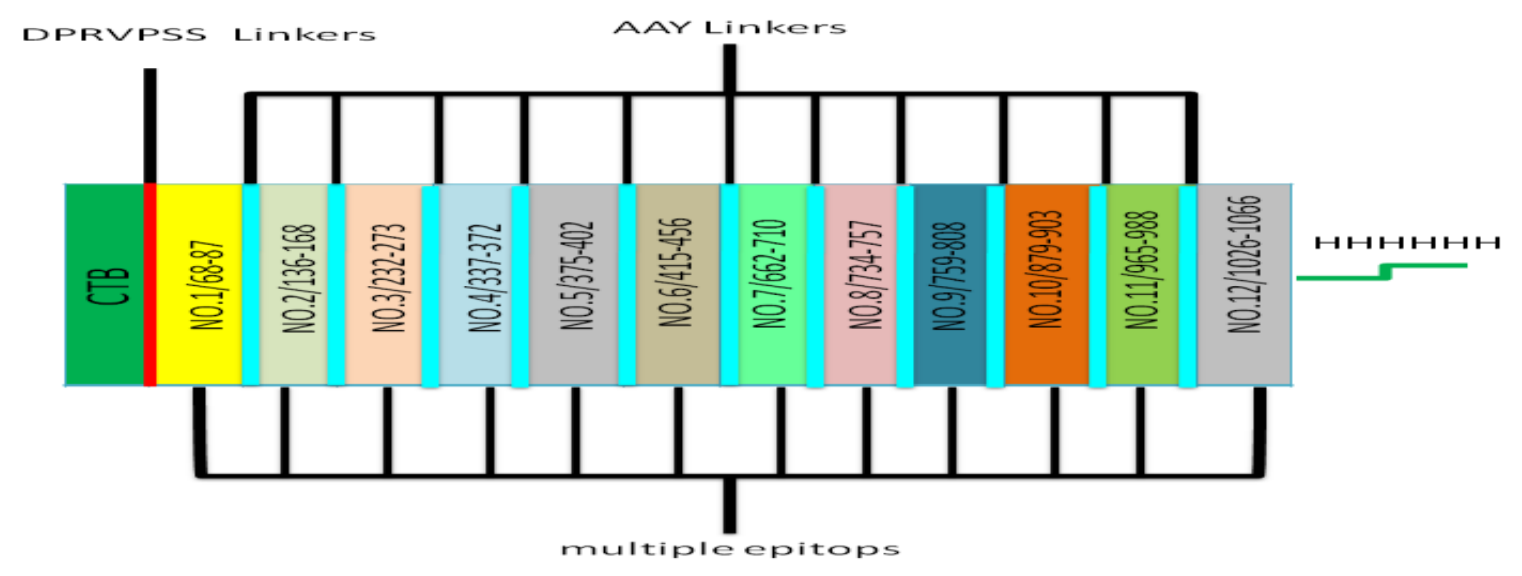

Figure 2. Schematic presentation of the final multi-epitope vaccine construct (582 residues long) containing an adjuvant (green) in N-terminal linked with 12 epitopes through a DPRVPSS linker (red). 12 epitopes fused together using AAY linkers (Light cyan). A 6x-His tag is added at the Carboxy terminus for purification and identification purposes. (CTB; cholera toxin subunit B)

A

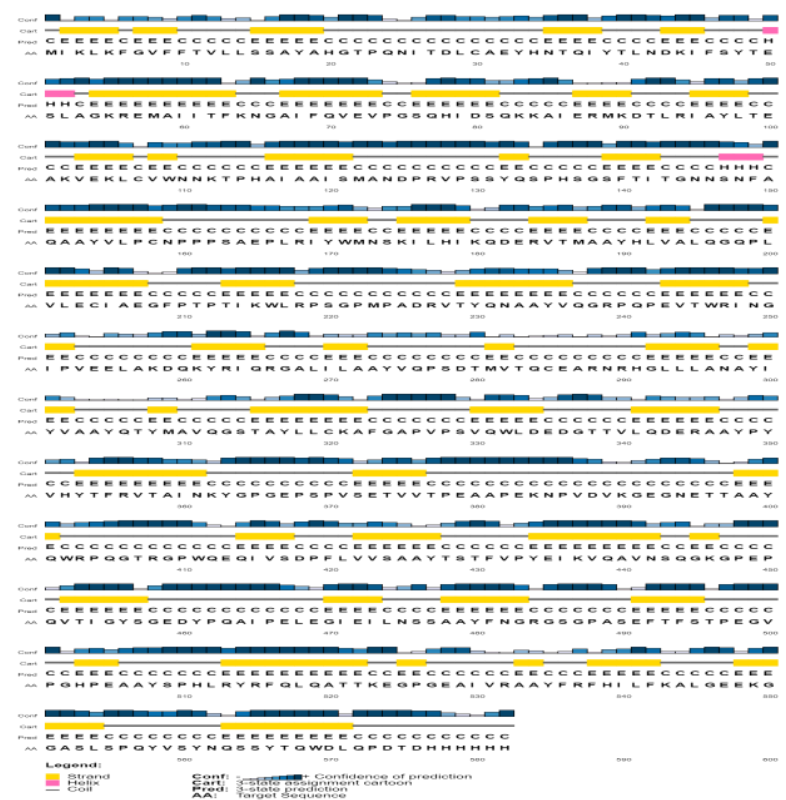

B

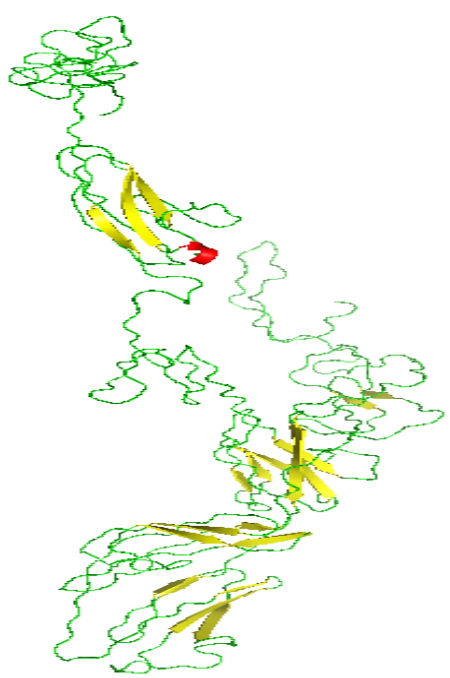

Figure 3. Prediction of the final vaccine structure. (A)PSIPRED predicted secondary structure of final chimeric peptide and (B) Predicted 3D model homology structure of final vaccine, helix, sheet and loop respectively are represented by red, yellow and green. 

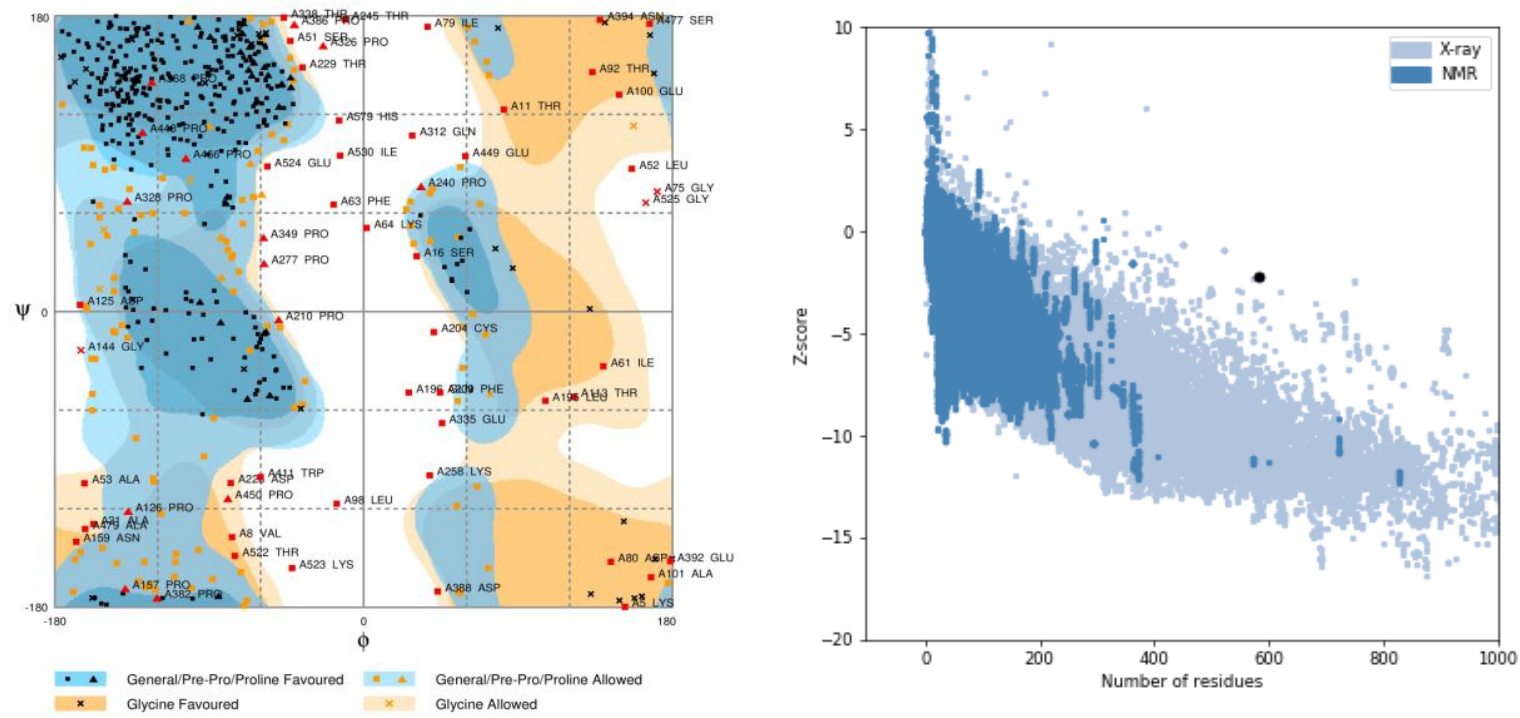

Figure 4.Tertiary structure modelling and validation. (A) Ramachandran plot of the final vaccine modeled and (B) ProSA-web, giving a Z-score of -2.25 .

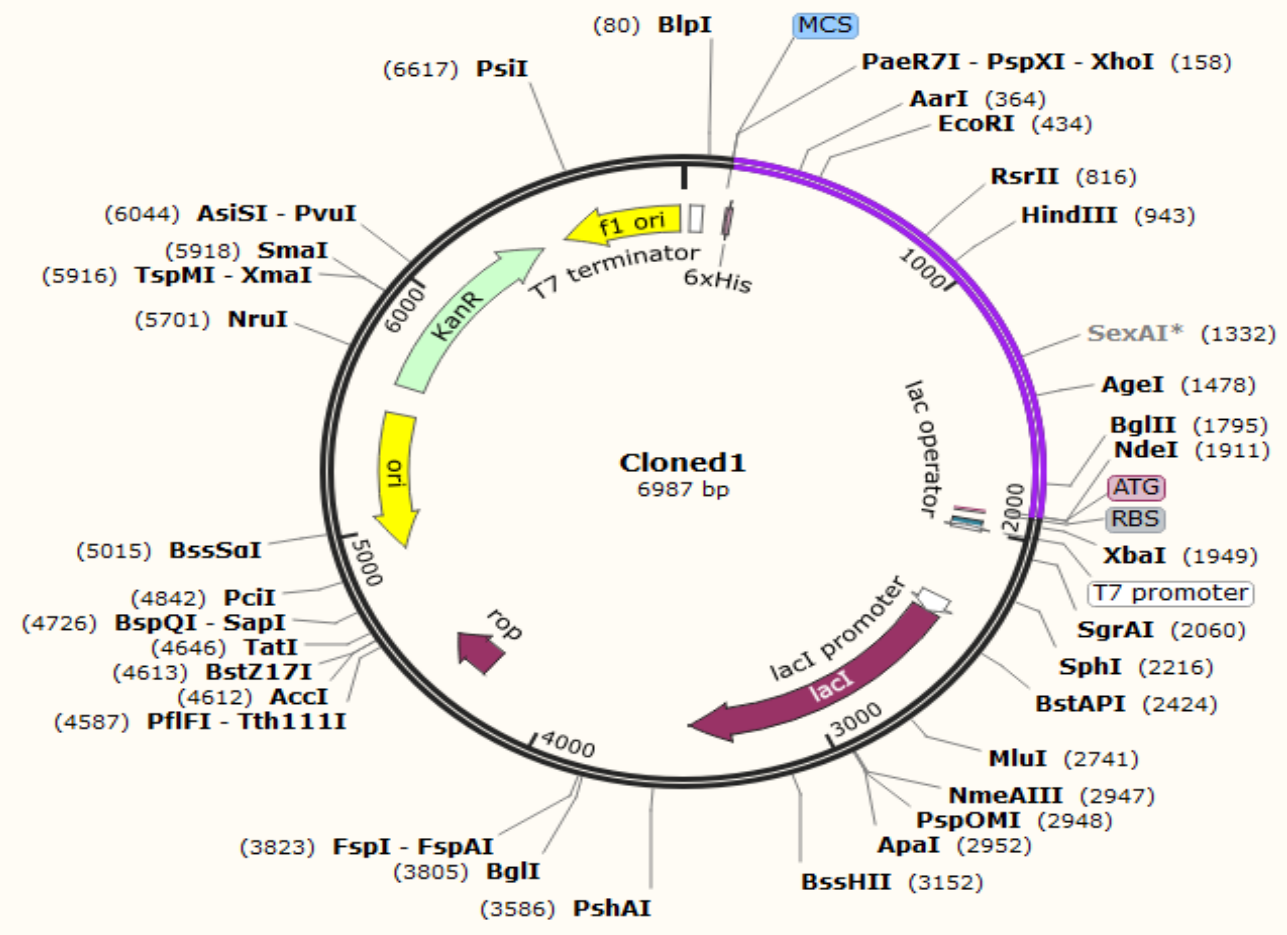

Figure 5. Final vaccine sequence in silico restriction cloning into the pET30a(+) expression vector where the purple part represents the vaccine gene coding and the vector backbone represented in the black circle. The His-tag is located at the carboxy-terminal end. 
Table 4. The CD171 multi-epitope vaccine.

\begin{tabular}{|c|c|c|c|c|c|c|c|c|c|}
\hline \multirow[t]{2}{*}{ NO. } & \multirow{2}{*}{ Sequence } & \multirow{2}{*}{ Position } & \multicolumn{2}{|c|}{$\begin{array}{l}\text { Count of } \\
\mathbf{T} \\
\text { Epitopes }\end{array}$} & \multirow{2}{*}{$\begin{array}{l}\text { Count } \\
\text { of B } \\
\text { Epitope } \\
\text { S }\end{array}$} & \multirow{2}{*}{$\begin{array}{l}\text { Ab } \\
\text { (Vaxije } \\
\text { n } \\
\text { score })\end{array}$} & \multirow[t]{2}{*}{ AllergenFP } & \multirow[t]{2}{*}{$\begin{array}{l}\text { AllerTO } \\
\text { P }\end{array}$} & \multirow[t]{2}{*}{ Toxicity } \\
\hline & & & $\begin{array}{l}\mathbf{C} \\
\mathbf{T} \\
\mathbf{L}\end{array}$ & $\begin{array}{l}\mathbf{H} \\
\mathbf{T} \\
\mathbf{L}\end{array}$ & & & & & \\
\hline 1. & YQSPHSGSFTITGNNSNFAQ & $68-87$ & 1 & 1 & 1 & $\begin{array}{l}0.9340 \\
\text { Proba } \\
\text { ble } \\
\text { antige } \\
\text { n }\end{array}$ & $\begin{array}{l}\text { PROBABL } \\
\text { E } \\
\text { ALLERGE } \\
\mathbf{N}\end{array}$ & $\begin{array}{l}\text { PROBA } \\
\text { BLE } \\
\text { ALLER } \\
\text { GEN }\end{array}$ & $\begin{array}{l}\text { Non- } \\
\text { Toxin }\end{array}$ \\
\hline 2. & $\begin{array}{l}\text { VLPCNPPPSAEPLRIYWMNSKIL } \\
\text { HIKQDERVTM }\end{array}$ & $136-168$ & 3 & 1 & 1 & $\begin{array}{l}0.6857 \\
\text { Proba } \\
\text { ble } \\
\text { antige } \\
\text { n }\end{array}$ & $\begin{array}{l}\text { PROBABL } \\
\text { E } \\
\text { ALLERGE } \\
\mathbf{N}\end{array}$ & $\begin{array}{l}\text { PROBA } \\
\text { BLE } \\
\text { NON- } \\
\text { ALLER } \\
\text { GEN }\end{array}$ & $\begin{array}{l}\text { Non- } \\
\text { Toxin }\end{array}$ \\
\hline 3. & $\begin{array}{l}\text { HLVALQGQPLVLECIAEGFPTPTI } \\
\text { KWLRPSGPMPADRVTYQN }\end{array}$ & $232-273$ & 1 & 1 & 1 & $\begin{array}{l}0.4400 \\
\text { Proba } \\
\text { ble } \\
\text { antige } \\
\text { n }\end{array}$ & $\begin{array}{l}\text { PROBABL } \\
\text { E NON- } \\
\text { ALLERGE } \\
\text { N }\end{array}$ & $\begin{array}{l}\text { PROBA } \\
\text { BLE } \\
\text { NON- } \\
\text { ALLER } \\
\text { GEN }\end{array}$ & $\begin{array}{l}\text { Non- } \\
\text { Toxin }\end{array}$ \\
\hline 4. & $\begin{array}{l}\text { VQGRPQPEVTWRINGIPVEELAK } \\
\text { DQKYRIQRGALIL }\end{array}$ & 337-372 & 1 & 1 & 1 & $\begin{array}{l}0.3826 \\
\text { Proba } \\
\text { ble } \\
\text { antige } \\
\text { n }\end{array}$ & $\begin{array}{l}\text { PROBABL } \\
\text { E NON- } \\
\text { ALLERGE } \\
\text { N }\end{array}$ & $\begin{array}{l}\text { PROBA } \\
\text { BLE } \\
\text { NON- } \\
\text { ALLER } \\
\text { GEN }\end{array}$ & $\begin{array}{l}\text { Non- } \\
\text { Toxin }\end{array}$ \\
\hline 5. & $\begin{array}{l}\text { VQPSDTMVTQCEARNRHGLLLA } \\
\text { NAYIYV }\end{array}$ & $375-402$ & 4 & 1 & 1 & $\begin{array}{l}0.4472 \\
\text { Proba } \\
\text { ble } \\
\text { antige } \\
n\end{array}$ & $\begin{array}{l}\text { PROBABL } \\
\text { E NON- } \\
\text { ALLERGE } \\
\text { N }\end{array}$ & $\begin{array}{l}\text { PROBA } \\
\text { BLE } \\
\text { NON- } \\
\text { ALLER } \\
\text { GEN }\end{array}$ & $\begin{array}{l}\text { Non- } \\
\text { Toxin }\end{array}$ \\
\hline 6. & $\begin{array}{l}\text { QTYMAVQGSTAYLLCKAFGAPV } \\
\text { PSVQWLDEDGTTVLQDER }\end{array}$ & $415-456$ & 5 & 3 & 1 & $\begin{array}{l}0.2626 \\
\text { Proba } \\
\text { ble } \\
\text { antige } \\
n\end{array}$ & $\begin{array}{l}\text { PROBABL } \\
\text { E NON- } \\
\text { ALLERGE } \\
\text { N }\end{array}$ & $\begin{array}{l}\text { PROBA } \\
\text { BLE } \\
\text { NON- } \\
\text { ALLER } \\
\text { GEN }\end{array}$ & $\begin{array}{l}\text { Non- } \\
\text { Toxin }\end{array}$ \\
\hline 7. & $\begin{array}{l}\text { PYVHYTFRVTAINKYGPGEPSPV } \\
\text { SETVVTPEAAPEKNPVDVKGEGN } \\
\text { ETT }\end{array}$ & $662-710$ & 2 & 4 & 1 & $\begin{array}{l}0.6377 \\
\text { Proba } \\
\text { ble } \\
\text { antige } \\
\text { n }\end{array}$ & $\begin{array}{l}\text { PROBABL } \\
\text { E NON- } \\
\text { ALLERGE } \\
\text { N }\end{array}$ & $\begin{array}{l}\text { PROBA } \\
\text { BLE } \\
\text { NON- } \\
\text { ALLER } \\
\text { GEN }\end{array}$ & $\begin{array}{l}\text { Non- } \\
\text { Toxin }\end{array}$ \\
\hline 8. & $\begin{array}{l}\text { QWRPQGTRGPWQEQIVSDPFLV } \\
\text { VS }\end{array}$ & 734-757 & 2 & 1 & 1 & $\begin{array}{l}0.5074 \\
\text { Proba } \\
\text { ble } \\
\text { antige } \\
\text { n }\end{array}$ & $\begin{array}{l}\text { PROBABL } \\
\text { E } \\
\text { ALLERGE } \\
\mathbf{N}\end{array}$ & $\begin{array}{l}\text { PROBA } \\
\text { BLE } \\
\text { ALLER } \\
\text { GEN }\end{array}$ & $\begin{array}{l}\text { Non- } \\
\text { Toxin }\end{array}$ \\
\hline
\end{tabular}




\begin{tabular}{|c|c|c|c|c|c|c|c|c|c|}
\hline 9. & $\begin{array}{l}\text { TSTFVPYEIKVQAVNSQGKGPEP } \\
\text { QVTIGYSGEDYPQAIPELEGIEIL } \\
\text { NSS }\end{array}$ & 759-808 & 3 & 2 & 1 & $\begin{array}{l}0.7410 \\
\text { Proba } \\
\text { ble } \\
\text { antige } \\
\text { n }\end{array}$ & $\begin{array}{l}\text { PROBABL } \\
\text { E NON- } \\
\text { ALLERGE } \\
\text { N }\end{array}$ & $\begin{array}{l}\text { PROBA } \\
\text { BLE } \\
\text { NON- } \\
\text { ALLER } \\
\text { GEN }\end{array}$ & $\begin{array}{l}\text { Non- } \\
\text { Toxin }\end{array}$ \\
\hline 10. & $\begin{array}{l}\text { FNGRGSGPASEFTFSTPEGVPGH } \\
\text { PE }\end{array}$ & $879-903$ & 1 & 4 & 1 & $\begin{array}{l}0.6699 \\
\text { Proba } \\
\text { ble } \\
\text { antige } \\
\text { n }\end{array}$ & $\begin{array}{l}\text { PROBABL } \\
\text { E NON- } \\
\text { ALLERGE } \\
\text { N }\end{array}$ & $\begin{array}{l}\text { PROBA } \\
\text { BLE } \\
\text { NON- } \\
\text { ALLER } \\
\text { GEN }\end{array}$ & $\begin{array}{l}\text { Non- } \\
\text { Toxin }\end{array}$ \\
\hline 11. & $\begin{array}{l}\text { SPHLRYRFQLQATTKEGPGEAIV } \\
\text { R }\end{array}$ & $965-988$ & 1 & 4 & 1 & $\begin{array}{l}0.6276 \\
\text { Proba } \\
\text { ble } \\
\text { antige } \\
\text { n }\end{array}$ & $\begin{array}{l}\text { PROBABL } \\
\text { E NON- } \\
\text { ALLERGE } \\
\text { N }\end{array}$ & $\begin{array}{l}\text { PROBA } \\
\text { BLE } \\
\text { NON- } \\
\text { ALLER } \\
\text { GEN }\end{array}$ & $\begin{array}{l}\text { Non- } \\
\text { Toxin }\end{array}$ \\
\hline 12. & $\begin{array}{l}\text { FRFHILFKALGEEKGGASLSPQY } \\
\text { VSYNQSSYTQWDLQPDTD }\end{array}$ & $\begin{array}{l}1026- \\
1066\end{array}$ & 4 & 2 & 1 & $\begin{array}{l}0.4705 \\
\text { Proba } \\
\text { ble } \\
\text { antige } \\
\text { n }\end{array}$ & $\begin{array}{l}\text { PROBABL } \\
\text { E } \\
\text { ALLERGE } \\
\text { N }\end{array}$ & $\begin{array}{l}\text { PROBA } \\
\text { BLE } \\
\text { NON- } \\
\text { ALLER } \\
\text { GEN }\end{array}$ & $\begin{array}{l}\text { Non- } \\
\text { Toxin }\end{array}$ \\
\hline
\end{tabular}

Table 5. Physicochemical properties of the vaccine candidate (MW: Molecular weight, Ii: Instability index, Ai: Aliphatic index and Ec: Extinction coefficient)

\begin{tabular}{|c|c|c|c|c|c|c|c|c|c|c|c|c|}
\hline Sequence & $\begin{array}{c}\text { LENG } \\
\text { TH }\end{array}$ & $\begin{array}{c}\text { Ab } \\
\text { (Vaxijen } \\
\text { score) }\end{array}$ & $\begin{array}{c}\text { Aller } \\
\text { genF } \\
\text { P }\end{array}$ & $\begin{array}{l}\text { Aller } \\
\text { TOP }\end{array}$ & GRAVY & PI & $\begin{array}{l}\text { MW } \\
\text { (Da) }\end{array}$ & $\begin{array}{c}\text { Solub } \\
\text { ility }\end{array}$ & $\begin{array}{c}\text { Half } \\
\text {-life } \\
\text { (h) }\end{array}$ & Ii & $\mathbf{A i}$ & $\begin{array}{c}\mathbf{E c} \\
\left(\mathbf{M}^{-}\right. \\
\left.{ }^{1} \mathbf{c m}^{-1}\right)\end{array}$ \\
\hline $\begin{array}{l}\text { YQSPHSGSFTITGNNSNFAQAAYV } \\
\text { LPCNPPPSAEPLRIYWMNSKILHIK } \\
\text { QDERVTMAAYHLVALQGQPLVLE } \\
\text { CIAEGFPTPIKWLRPSGPMPADR } \\
\text { VTYQNAAYVQGRPQPEVTWRING } \\
\text { IPVEELAKDQKYRIQRGALILAAY } \\
\text { VQPSDTMVTQCEARNRHGLLLAN } \\
\text { AYIYVAAYQTYMAVQSTAYLLC } \\
\text { KAFGAPVPSVQWLDEDGTTVLQD } \\
\text { ERAAYPYVHYTFRVTAINKYGPGE } \\
\text { PSPVSETVVTPEAAPEKNPVDVKG } \\
\text { EGNETTAAYQWRPQGTRGPWQE } \\
\text { QIVSDPFLVVSAAYTSTFVPYEIKV } \\
\text { QAVNSQGKGPEPQVTIGYSGEDYP } \\
\text { QAIPELEGIEILNSSAAYFNGRGSG } \\
\text { PASEFTFSTPEGVPGHPEAAYSPHL } \\
\text { RYRFQLQATTKEGPGEAIVRAAYF } \\
\text { RFHILFKALGEEKGGASLSPQYVS } \\
\text { YNQSSYTQWDLQPDTD HHHHHH }\end{array}$ & 451 & $\begin{array}{c}0.5022 \\
\text { Probable } \\
\text { antigen }\end{array}$ & $\begin{array}{l}\text { PRO } \\
B A B \\
L E \\
N O N- \\
A L L E \\
R G E \\
N\end{array}$ & $\begin{array}{l}P R O \\
B A B \\
L E \\
A L L E \\
R G E \\
N\end{array}$ & -0.429 & 5.79 & $\begin{array}{l}49898 \\
.87\end{array}$ & $\begin{array}{l}\text { Poor } \\
\text { water } \\
\text { solubi } \\
\text { lity }\end{array}$ & 2.8 & $\begin{array}{l}4 \\
4 . \\
7 \\
5\end{array}$ & $\begin{array}{l}71 . \\
42\end{array}$ & $\begin{array}{l}81710 \\
- \\
81960\end{array}$ \\
\hline
\end{tabular}

